\title{
Book Review: Martin Barker,
}

\section{Clarissa Smith and Feona}

Attwood, Watching Game of Thrones: How Audiences

Engage with Dark Television (Manchester: Manchester University Press, 2021)
ब나

Open Library of Humanities

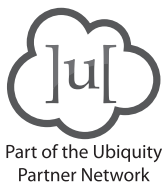

CORRESPONDING AUTHOR: Louise Coopey

University of Birmingham, GB LJC385@student.bham.ac.uk

KEYWORDS:

Television; Game of

Thrones; audience research; qualiquantitative research; popular media

TO CITE THIS ARTICLE:

Coopey, L. 2021. Book Review: Martin Barker, Clarissa Smith and Feona Attwood, Watching Game of Thrones: How Audiences Engage with Dark Television (Manchester: Manchester University Press, 2021). Open Screens, 4: 20, pp. 1-4. DOI: https://doi. org/10.16995/os.8021 


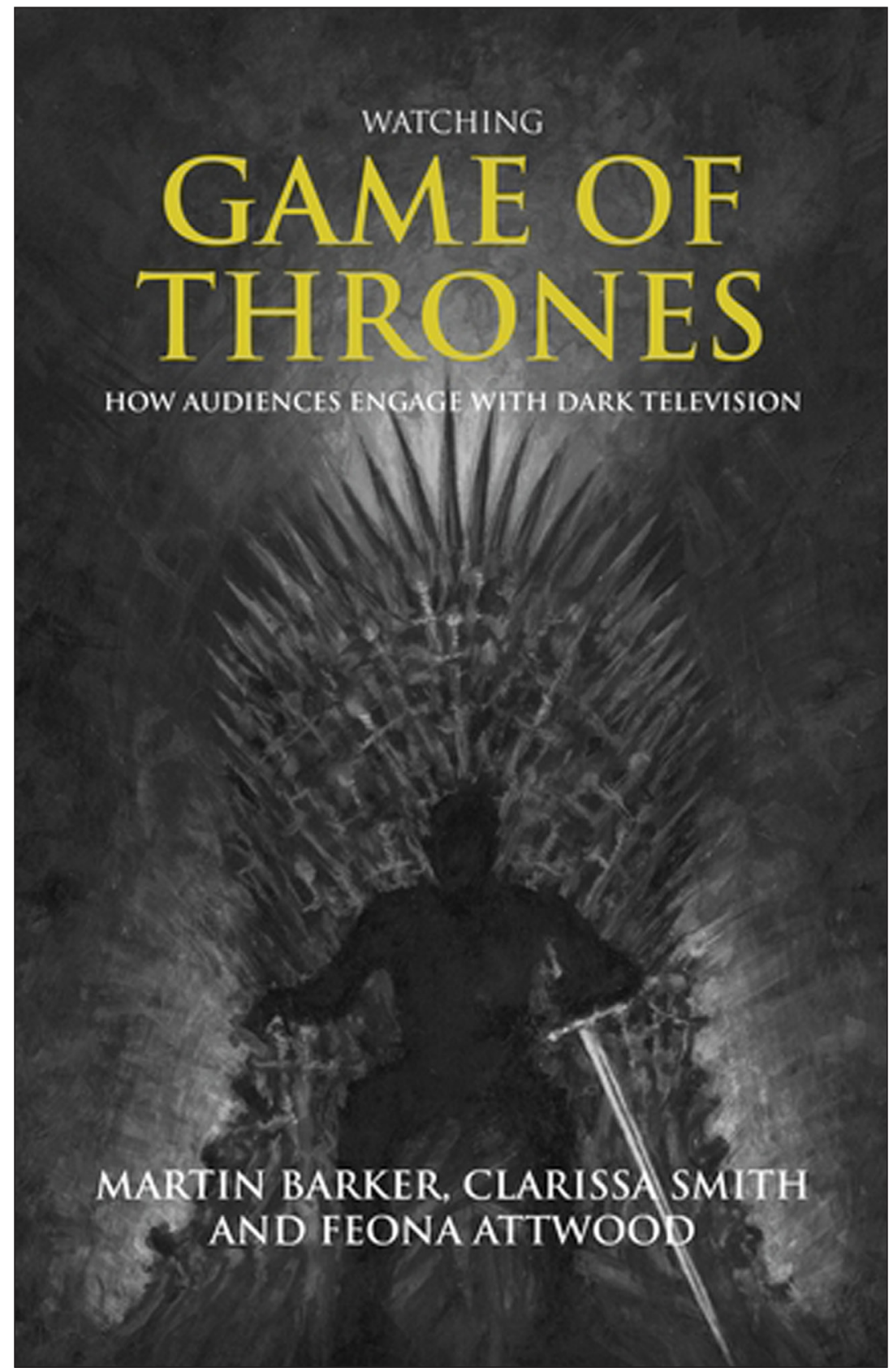

In Watching Game of Thrones (2021), authors Martin Barker, Clarissa Smith and Feona Attwood accurately describe Game of Thrones (2011-2019) as 'a cultural phenomenon of real import and impact' (1). It may therefore come as somewhat of a surprise that their book is the first comprehensive investigation into the show's audiences. Built on analysis of international audience research, the authors move beyond the conventional approaches to television audiences of escapism and identification to focus on viewer response and judgement based on how and why individuals watch(ed) Game of Thrones.

The scale of the project that forms the basis of Watching Game of Thrones is extensive, involving 42 academics in 14 countries and 10,636 questionnaire responses. The project purposefully captured sufficient data to explore five defined areas of interest - types of audience, favourite characters and survivors, the tendency to seek metaphorical meanings in the show, conflicts and controversies and the implications of the unpredictability of the show - each of which offer an insight into the viewers of Game of Thrones and how their activities impact on their reading and meaning-making of the text.

Despite the absence of a working hypothesis, the book develops an understanding of the significance of Game of Thrones to different kinds of audiences and determines how viewers situate their responses to the show. This is a common thread that runs from the introduction to the postscript, unifying the analysis and ensuring its cohesion throughout. One such unifying element is the categorisation of the different types of Game of Thrones audiences outlined in the third chapter. The determination of different orientations based on the reasons viewers watched, their ways of watching, their activities associated with Game of Thrones and 
the dominant feelings and attitudes produced is highly effective. However, the authors also create some ambiguity here. They contend that this approach is key to moving beyond the more conventional labels applied to people who watch Game of Thronesviewers, spectators, fans, enthusiasts, geeks-and the judgements they so often carry. Although they do avoid simple categorisation and reductive labelling of audiences, labels are still central to the analysis. Indeed, Barker, Smith and Attwood do not shy away from redefining existing categories in line with their findings. For instance, they acknowledge that one of their categories, 'Fan Watchers' (later 'World Watchers'), are aligned with the 'lurkers' that 'supposedly hang around on the Internet watching- and sometimes rudely intervening onto- proper fans' interests and activities' (38), as per Nonnecke et al. (2004) and Preece et al. (2004). The authors' excellent reorientation of conceptions of this type of audience challenges existing negative connotations of them and notes a greater level of complexity in their engagement with television than had been previously acknowledged.

Furthermore, the authors' favoured qualiquantiative methodological approach successfully produces 'richly structured combination of data and discourses' (17) and is a fundamental strength of the project. The combination of demographic data, scaled responses and explanations, insights into key areas like favourite survivors and memorable moments and wildcard questions to delve into engagement produces layered knowledge without being constrained by methods. Further, it identifies patterns that allow for collective insights without stifling individual voices. In this sense, Barker, Smith and Attwood develop an approach to audience research that engages with and produces reflections on the complexity of audiences via relevant social, cultural and historical processes and contextual factors.

The patterns of engagement observed are typically highlighted and investigated via the juxtaposition of two specific responses. For instance, the significance of favourite character choices in chapter five is exemplified by two very different readings of the selection of Jon Snow. The authors observe that ideologically right-wing men typically select Jon because he is a natural born leader whereas women read him as a 'Jane Austenesque' hero, thus both display 'a wider attraction to a kind of masculinity' (81). The discourses surrounding the two positions are intriguing and highlight the very different results that engagement produces. I found myself disagreeing with respondents in some cases- the idea that Petyr 'Littlefinger' Baelish has moral principles being a notable example (64) - but this stands in stark contrast to the authors' refusal to take 'sides' (117).
Barker, Smith and Attwood deliberately avoid value judgements and, in doing so, are able to authoritatively unpick the complex processes that underpin viewing experiences throughout.

No analysis of Game of Thrones is complete without a discussion of at least one of its well-documented controversies and Watching Game of Thrones does not disappoint. Although some controversies, like the Red Wedding and the rape of Sansa Stark, are explored via the questionnaire data, the authors' willingness to deviate from that research material to discuss the most recent controversy (the high level of dissatisfaction with the ending of the series) was particularly welcome. Although the questionnaire data collection occurred in 2016 and 2017, and was thus prior to the broadcast of seasons seven and eight of the show, it seems fitting that Barker, Smith and Attwood add a postscript reflecting on audience responses to the narrative and character endings deployed by the showrunners, David Benioff and D. B. Weiss. The authors explore the comments on a petition that was launched on change.org which demanded a remake of the eighth season. They correctly point out that the problem of ending a television show is not a new phenomenon but also observe that the Game of Thrones ending has added further layers to that problem, not least that closure and finality are not the only ways of understanding it. Although limited and somewhat speculative in comparison to the rest of the book, a fact that the authors freely admit, it nonetheless offers a further valuable facet of the insightful analysis produced in Watching Game of Thrones.

In short, while the scope of analysis is limited by the parameters of the book's remit given the sheer amount of data collected, Watching Game of Thrones is an engaging source of debate and a valuable contribution to the field of television audience research, notably to the question of how audience studies projects may be constructed and the depth of analysis that is possible. It also significantly enhances the scholarship specifically focused on Game of Thrones itself, moving beyond existing speculative observations on the show's audiences with authoritative research and analysis that empower them to speak for themselves.

\section{COMPETING INTERESTS}

The author has no competing interests to declare.

\section{AUTHOR AFFILIATION}

Louise Coopey (D) orcid.org/0000-0003-1762-3354

University of Birmingham, GB 
TO CITE THIS ARTICLE:

Coopey, L. 2021. Book Review: Martin Barker, Clarissa Smith and Feona Attwood, Watching Game of Thrones: How Audiences Engage with Dark Television (Manchester: Manchester University Press, 2021). Open Screens, 4: 20, pp. 1-4. DOI: https://doi.org/10.16995/os.8021

Submitted: 21 October 2021 Accepted: 21 October 2021 Published: 11 November 2021

COPYRIGHT:

(c) 2021 The Author(s). This is an open-access article distributed under the terms of the Creative Commons Attribution 4.0 International License (CC-BY 4.0), which permits unrestricted use, distribution, and reproduction in any medium, provided the original author and source are credited. See http://creativecommons.org/licenses/by/4.0/.

Open Screens is a peer-reviewed open access journal published by Open Library of Humanities. 